\title{
Doğum Korkusunun Gebelik Haftası ve Sayısı ile İlişkisi
}



${ }^{1}$ Muş Devlet Hastanesi, Kadın Hastalıkları ve Doğum Kliniği, Muş, Türkiye

${ }^{2}$ Karacabey Devlet Hastanesi, Kadın Hastalıkları ve Doğum, Bursa, Türkiye

Mehmet Musa Aslan, 0p. Dr. İsmail Bıyık, 0p. Dr.

Illetişim:

Op. Dr. Mehmet Musa Aslan

Muş Devlet Hastanesi, Kadın Hastalıkları ve Doğum Kliniği, Muş, Türkiye Tel: +9053263647 06

E-Posta:jinopdrmma@gmail.com

\section{ÖZET}

Amaç: Bu çalışmada doğum korkusunun gebelik haftası ve sayısı ile ilişkisi araştıııldı

Hastalar ve Yöntem: Ocak 2018 -Kasım 2018 tarihleri arasında Muş Devlet Hastanesi gebe bilgilendirme sınıfına başvuran gebelere Gebelik Oncesi Doğum Korkusu ölçeği doldurtuldu.

Bulgular: Gebeliğin üçüncü üç ayında eğitim alanlar birinci üç ayda eğitim alanlara göre daha fazla 'doğumla baş edemeyeceklerini' düşünürken ve 'doğum ağrıları ve doğum sırasında paniklemekten ve ne yapacaklarını bilememekten' korkmaktadır (sırasıyla $p=0.012$ ve $p=0.004$ ). Gebelik üçüncü üç ayında eğitim alan gebeler 'doğumda bebeklerine zarar gelmesinden' 'doğumun bebeklerine zarar vermesinden' ve 'doğum ağrıları ve doğum sırasında bir sorun gelişeceğinden' ilk üç aydakilere oranla daha çok korkmaktadır (sırasıyla $p<0.001$ ve $p=0.013$ ). Doğum ağrıları ve doğumun bedeninde bırakacağı etkilerden korkanlar ilk üç ayındaki gebelerde daha fazladır $(p=0.022)$. Primigravid gebelerin doğum korkusu ölçek puanı, multipar gebelere göre daha yüksek bulundu $(<0.001)$.

Sonuçlar: Gebeliğin ilk aylarındakiler doğumun bedeninde bırakacağı etkiler konusunda kaygı duymaktadırlar. Gebelik ilerledikçe doğum eylemi ile başa çıkamama ve bebeğin sağığı ile ilgili kaygılar ön plana çıkmaktadır. Doğum korkusu primigravidlerde daha fazladır. Gebeliğin son haftalarında özellikle primigravid gebelerin doğum korkularını azaltacak eğitimlere ağırlık verilmelidir.

Anahtar sözcükler: Doğum korkusu, gebe bilgilendirme, doğum, korku

\section{THE RELATIONSHIP BETWEEN FEAR OF CHILDBIRTH LEVEL GESTATIONAL AGE AND NUMBER OF PREGNANCIES}

\section{ABSTRACT}

Purpose: In this study, the relationship between gestational week, number of pregnancies and fear of childbirth was investigated.

Patients and methods: The study was conducted between January 2018 and November 2018. The Childbirth Fear - Prior to Pregnancy scale Turkish version was filled for the pregnant women who applied to Muş State Hospital Pregnancy Information Class.

Results: In the third trimester of pregnancy, those receiving education of fear that 'they might panic and not know what to do during labour $\&$ birth.' $(p=0.012$ and $p=0.004$, respectively). In the third trimester, they were worried that harm might come to the baby and had fear of complications during labour and birth more than the first-trimester pregnants $(p<0.001$ and $p=0.013$, respectively). In the first three months of pregnancy, the fact that they were afraid of what the labour and birth process will do to their bodies were more common $(p=0.022)$. Fear of childbirth was found higher in primigravid pregnant women than multiparous women $(<0.001)$.

Conclusion: In the first three months of pregnancy, they are afraid of what the labour and birth process will do to their bodies. As the pregnancy progresses, fear that they will lose control during labour and birth increased and they think labour and birth process might harm the baby.Emerge fear of childbirth is higher in primigravidae. In the last weeks of pregnancy, antenatal education that alleviates the fear of childbirth might be focused on primigravid pregnant women.

Keywords: Fear of childbirth, pregnancy education, birth, fear 
Ikemizde sezaryen doğum oranı 2017 yılı \%53 olarak hesaplanmıştır (1). Bu oran Dünya Sağlık Örgütünün \%15 hedefinin çok üzerindedir. Doğum korkusuna bağlı anne isteğinin sezaryen oranlarını artırdığı bilinmektedir. Kadınlarda doğum korkusu prevelansı \%20 olup, doğum eylemini etkiyebilecek düzeyde korku prevelansı \%6-13 olarak bildirilmiștir $(2,3)$. Doğum korkusu temelde olası maternal komplikasyonlar, doğumda kontrolü kaybetme korkusu, sağlık personelinin ilgisiz davranacağı düşüncesi ve doğumda bebeğe zarar gelme endişesinden doğmaktadır (4-8). Doğum korkusu doğum eyleminin uzaması riskini artırmaktadır $(9,10)$. Ayrıca hastaların posttravmatik stres bozukluğu yaşama intimalini artırmaktadır (11). Doğum korkusu tıbbi bir neden olmaksızın anne isteğine bağlı sezaryen oranlarını artıran önemli bir nedendir (1215). Doğum korkusu nullipar gebelerde multiparlara oranla daha fazla görülmektedir $(5,16,17)$. Doğum korkusu gebelik haftası ile ilişkisiz bulunmuştur $(16,18,19)$.

Bu çalışmamızda doğum korkusu şiddetinin gebelik sayısı ve gebelik haftasına göre ilişkisi araştırıldı.

\section{Gereç ve Yöntem}

Olgu seçimi

Prospektif kohort çalışmasına Muş Alpaslan Üniversitesi İnvaziv Olmayan Araştırmalar etik kurulandan alınan onayı takiben başlandı. Çalışmaya 18-42 yaş arası tekil gebeler dahil edildi. Türkçe bilmeyen, mental retarde, konuşma yada işitme engeli bulunan, psikiyatrik hastalığı (psikoz vs) nedeniyle sorulan soruları anlayamayan gebeler ile önceki doğumu sezaryen ile gerçekleşmiş olanlar çalışma dışı bırakıldı.

\section{Gebe bilgilendirme sınıfi}

Gebe bilgilendirme sınıflarında gebeliğin birinci, ikinci, üçüncü üç ayı ve lohusalık dönemlerinde gebelere bilgiler verilmektedir. İlk üç ayda üreme organlarının anatomi ve fizyolojisi, gebeliğin nasıl oluştuğu, gebelik takibi ve gebelikte beslenme gibi konularda eğitimler verilmektedir. Íkinci üç ayda doğum eylemi hakkında genel bilgiler, pelvik taban egzersizleri ve doğum sancısı ile başa çıkma yöntemleri hakkında bilgiler verilmektedir. Üçüncü üç ayda doğum eylemi hakkında detaylı bilgiler verilmekte, anne-bebek bağlanması hakkında gebeler bilgilendirilmektedir. Lohusalar için lohusalıkta fizyolojik değişiklikler ile korunma yöntemleri hakkında bilgiler verilmektedir (20).

\section{Veri toplama}

Ocak 2018 ile Kasım 2018 tarihleri arasında Muş Devlet Hastanesi gebe bilgilendirme sınıfına başvuran gebelere verilen eğitim sonrası Türkçe geçerlik güvenirliği sağlanmış
Kadın Gebelik Öncesi Doğum Korkusu Ölçeği dolduruldu (21). Gebelik Oncesi Doğum Korkusu genc kadın ve erkeklerin gebelik oncesi doğum korkusunu olçebilen, kişinin kendisi tarafından doldurulabilen bir ölcektir. Olcek doğum korkusuna en cok neden olan boyutları içermektedir: doğum ağrısı, kontrol kaybı, doğum ağrısı ve doğumla baş edememe, komplikasyonlar ve geri donuşumu olmayan fiziksel hasarlar. On maddeden oluşan ölçekteki yanıtlar 1'den 6'ya kadar numaralandırımış olup, altılı likert tiptedir. Bir "kesinlikle katılmıyorum", 2 "katılmıyorum", 3 "kısmen katılmıyorum", 4"kısmen katılıyorum, 5"katılıyorum", 6"kesinlikle katılıyorum" şeklinde ifade edilmektedir. Ölcekte minimum puan 10 iken, maksimum puan 60 'dir. Madde toplam puanın yüksek olması yuksek duzeyde korkuyu göstermektedir.

Toplam 230 gebe ile çalışma gerçekleştirildi. Çalışmaya dahil edilen olgular üç gruba ayrıldı. Yalnızca gebeliğin ilk üç ayında eğitim alan 38 olgu, ikinci üç aya eğitim alanlar 37 olgu ve gebeliğin üçüncü üç ayında eğitim alan 155 olgu olmak üzere olgular üç gruba ayrıldı. Primigravid ile multipar gebeliği olanlarda ayrıca karşılaştırıldı.

\section{Istatiksel analiz}

Tanımlayıcı değerler ortalama \pm SD ve sayı ve \%frekanslar halinde verilmiştir. Sayısal özelliklerin normal dağılım testinde Kolmogorov-Smirnov testi kullanıldı. Normal dağılım gösteren sayısal özellikler bakımından grupların karşılaştırılmasında tek yönlü varyans analizi kullanıldı ve anlamlı düzeyde farklı olan gruplar post Hoc Tukey testi ile belirlendi. Kategorik yapıdaki özellikler ile gruplar arasındaki ilişkiler ki-kare testi ile incelendi. Bağımlı değişkenler arasındaki ilişki pearson korelasyon analizi ile araştırıldı. İstatistik anlamlılık düzeyi olarak $p \leq 0.05$ alındı ve bütün istatistik hesaplamalar PASW (ver. 21) programında yapıldı.

\section{Bulgular}

Olguların yaş ortalaması 23,54 yıl olarak bulundu. illk üç ayındaki gebeler, ikinci ve üçüncü üç ayındaki gebelere göre daha eğitimli olarak bulundu $(p<0.001)$. Hipertansiyonu bulunan gebe oranı ilk üç ayda eğitim alanlarda, ikinci ve üçüncü üç ayda eğitim alanlara göre daha azdı $(p=0.001)$. Her üç grup arasında yaş, çalışma durumu ve gebelik sayısı açısından anlamlı fark bulunmadı ( $p>0.005$ ). Olguların demografik verileri Tablo 1'de verildi.

Eğitim düzeyi arttıkça doğum korkusu ölçek toplam puanının arttığı bulundu $(p<0,001)$. Yaş ile doğum korkusu toplam puanı arasında negatif korelasyon bulundu $(p<0,001, r-431)$. Bir işte çalışanlar ile çalışmayanların doğum korkusu ölçek puanları benzer bulundu ( $p>0.005)$. 
Tablo 1. Olguların demografik özelliklerinin gebelik ayına göre karşılaştırıması

\section{Gebelik Ayı}

\begin{tabular}{lcccc}
\hline Alt grup & $\begin{array}{c}\text { Ilk üç ay } \\
(\boldsymbol{n}=38)\end{array}$ & $\begin{array}{c}\text { ikinci üç ay } \\
(\boldsymbol{n}=37)\end{array}$ & $\begin{array}{c}\text { Üçüncü üç ay } \\
(\boldsymbol{n}=\mathbf{1 5 5})\end{array}$ & $\boldsymbol{P}^{*}$ \\
\hline Yaş (yıl) & $21,94 \pm 3,89$ & $23,10 \pm 5,11$ & $24,04 \pm 6,43$ & $>0.05$ \\
\hline Eğitim & & & & \\
Okuryazar değil & $2(\% 5,3)$ & $12(\% 32,4)$ & $52(\% 33,5)$ & \\
Okuryazar & $7(\% 18,4)$ & $13(\% 35,1)$ & $32(\% 20,6)$ & $<0.001$ \\
Illköğretim & $21(\% 55,3)$ & $12(\% 32,4)$ & $71(\% 45,8)$ & \\
Lise & $8(\% 21)$ & 0 & 0 & \\
İ̧̧ & & & & \\
Çalışıyor & $1(\% 2,6)$ & 0 & $4(\% 2,6)$ & $>0.05$ \\
Çalışmıyor & $37(\% 97,4)$ & $37(\% 100)$ & $151(\% 97,4)$ & \\
\hline
\end{tabular}

\section{Kronik hastalık}

Yok

$30(\% 78,9) \quad 24(\% 64,9) \quad 111(\% 71,6)$

Kalp hastalığı

0

$3(\% 1,3)$

0

Diyebet

Hipertansiyon $3(\% 7,9)$

0

$2(\% 5,4)$

$14(\% 9)$

$7(\% 18,9)$

$22(\% 14,2)$

$=0.001$

Tiroid bozukluğu $4(\% 10,5)$

$1(\% 2,7)$

$8(\% 5,2)$

Astım

$1(\% 2,6)$

0

0

\section{Gebelik sayısı}

Primigravid

Multipar

$27(\% 71,1) \quad 19(\% 51,4) \quad 87(\% 56,1$

$11(\% 28,9) \quad 18(\% 48,69 \quad 68(\% 43,9)$

$>0.05$

*ki-kare testi

Tablo 2. Gebelik Oncesi Doğum Korkusu ölçeğinin sonuçlarının gebelik ayına göre karşılaştırımas

\begin{tabular}{|c|c|c|c|c|}
\hline & & Gebelik Ayı & & \\
\hline & $\begin{array}{c}\text { İlk üç ay } \\
(n=38)\end{array}$ & $\begin{array}{c}\text { İkinci üç ay } \\
(n=37)\end{array}$ & $\begin{array}{c}\text { Üçüncü üç ay } \\
(n=155)\end{array}$ & $p^{p *}$ \\
\hline Doğum ağrısının çok şiddetli olacağından endişe duyuyorum & $4,52 \pm 0.60$ & $4,24 \pm 0,66$ & $4,23 \pm 049$ & $>0.05$ \\
\hline Doğum ağrısıyla baş edemeyeceğimi düşünüyorum & $5,00 \pm 0,23$ & $5,05 \pm 0,74$ & $5,27 \pm 0,51$ & $\begin{array}{l}p=0.014 \\
p 1=0.012\end{array}$ \\
\hline $\begin{array}{l}\text { Doğum ağrıları ve doğum sırasında paniklemekten ve ne yapacağımı } \\
\text { bilememekten korkuyorum }\end{array}$ & $5,00 \pm 0,23$ & $5,05 \pm 0,74$ & $5,27 \pm 0,51$ & $\begin{aligned} p & =0.004 \\
p 1 & =0.013\end{aligned}$ \\
\hline Doğumdan çok korkuyorum & $5,00 \pm 0,23$ & $4,91 \pm 0,59$ & $4,86 \pm 0,52$ & $>0.05$ \\
\hline Doğumda bebeğe zarar gelmesinden endişeleniyorum & $4,76 \pm 0,54$ & $5,48 \pm 0,60$ & $5,43 \pm 0,59$ & $\begin{array}{l}\mathrm{p}<0.001 \\
\mathrm{p} 1=0.001\end{array}$ \\
\hline Doğum ağrıları ve doğum sırasında kontrolümü kaybetmekten korkuyorum & $5,00 \pm 0,23$ & $4,81 \pm 0,56$ & $4,94 \pm 0,42$ & $>0.05$ \\
\hline Doğum ağrıları ve doğum sırasında bir sorun gelişeceğinden korkuyorum & $5,00 \pm 0,23$ & $5,13 \pm 0,48$ & $5,23 \pm 0,46$ & $\begin{array}{l}p=0.013 \\
p 1=0.011\end{array}$ \\
\hline Doğum öngörülemez ve riskli bir durumdur & $4,65 \pm 0,74$ & $4,37 \pm 0,72$ & $4,43 \pm 0,60$ & $>0.05$ \\
\hline Doğum ağrıları ve doğumun bedenimde bırakacağı etkilerden korkuyorum & $1,71 \pm 0,45$ & $1,62 \pm 0,54$ & $1,44 \pm 0,61$ & $\begin{array}{l}p=0.022 \\
p 1=0.033\end{array}$ \\
\hline Doğumdan sonra vücudumun bir daha eskisi gibi olmayacağından korkuyorum & $1,71 \pm 0,45$ & $1,59 \pm 0,49$ & $1,46 \pm 0,64$ & $>0.05$ \\
\hline Toplam puan & $42,28 \pm 2,48$ & $41,89 \pm 4,08$ & $41,99 \pm 3,74$ & $>0.05$ \\
\hline
\end{tabular}

Gebeliğin üçüncü üç ayında eğitim alanlar birinci üç ayda eğitim alanlara göre daha fazla 'doğumla baş edemeyeceklerini' düşünürken 'doğum ağrıları ve doğum sırasında paniklemekten ve ne yapacaklarını bilememekten'korkmaktadır (sırasıyla $p=0.012$ ve $p=0.004$ ). Gebelik üçüncü üç ayında eğitim alan gebeler 'doğumda bebeklerine zarar gelmesinden' 'doğumun bebeklerine zarar vermesinden' ve 'doğum ağrıları ve doğum sırasında bir sorun gelişeceğinden' ilk üç aydakilere oranla daha çok korkmaktadır (sırasıyla $p<0.001$ ve $p=0.013$ ). Doğum ağrıları ve doğumun bedeninde bırakacağı etkilerden korkanlar ilk üç ayındaki gebelerde daha fazladır ( $p=0.022$ ). Olguların gebelik ayına göre gebelik öncesi doğum korkusu ölçek puanları Tablo 2'de karşılaştıııldı. İstatiksel olarak anlamlı ölçek soruların puanlarının gebelik haftasına göre değişimi Şekil 1'de verildi.

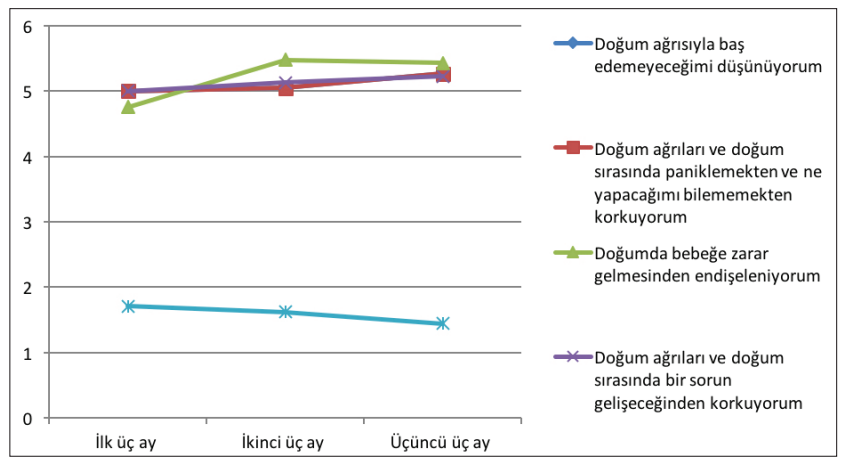

Şekil 1. Gebelik Öncesi Doğum Korkusu Ölçeği soru puanlarının gebelik haftasına göre değişimi 


\begin{tabular}{|c|c|c|c|}
\hline & \multicolumn{2}{|c|}{ Gebelik sayısı } & \multirow[b]{2}{*}{$P *$} \\
\hline & $\begin{array}{c}\text { Primigravid } \\
(n=133)\end{array}$ & $\begin{array}{c}\text { Multipar } \\
(n=97)\end{array}$ & \\
\hline Doğum ağrısının çok şiddetli olacağından endişe duyuyorum & $4,99 \pm 0.08$ & $4,29 \pm 0,97$ & $<0.001$ \\
\hline Doğum ağrısıyla baş edemeyeceğimi düşünüyorum & $4,47 \pm 0,57$ & $4,03 \pm 0,41$ & $<0.001$ \\
\hline Doğum ağrıları ve doğum sırasında paniklemekten ve ne yapacağımı bilememekten korkuyorum & $5,41 \pm 0,49$ & $4,88 \pm 0,43$ & $<0.001$ \\
\hline Doğumdan çok korkuyorum & $4,93 \pm 0,49$ & $4,84 \pm 0,50$ & $>0.05$ \\
\hline Doğumda bebeğe zarar gelmesinden endişeleniyorum & $5,42 \pm 0,63$ & $5,21 \pm 0,63$ & $=0.016$ \\
\hline Doğum ağrıları ve doğum sırasında kontrolümü kaybetmekten korkuyorum & $4,99 \pm 0,46$ & $4,85 \pm 0,35$ & $=0.016$ \\
\hline Doğum ağrıları ve doğum sırasında bir sorun gelişeceğinden korkuyorum & $5,31 \pm 0,46$ & $4,98 \pm 0,33$ & $<0.001$ \\
\hline Doğum öngörülemez ve riskli bir durumdur & $4,51 \pm 0,69$ & $4,39 \pm 0,58$ & $>0.05$ \\
\hline Doğum ağrıları ve doğumun bedenimde bırakacağı etkilerden korkuyorum & $1,76 \pm 0,58$ & $1,17 \pm 0,38$ & $<0.001$ \\
\hline Doğumdan sonra vücudumun bir daha eskisi gibi olmayacağından korkuyorum & $1,78 \pm 0,60$ & $1,17 \pm 0,38$ & $<0.001$ \\
\hline Toplam puan & $43,60 \pm 3,50$ & $39,86 \pm 2,45$ & $<0.001$ \\
\hline
\end{tabular}

Primigravid gebeler, multipar gebelere göre doğum konusunda daha endişeli bulundu $(<0.001)$. Primigravid gebelerin 'doğum ağrısının çok şiddetli olacağından', doğum ağrısıyla baş edemeyeceklerinden', 'doğum ağrıları ve doğum sırasından paniklemekten ve ne yapacağını bilememekten" 'doğumda bebeklerine zarar gelmesinden', 'doğum ağrıları ve doğum sırasında kontrollerini kaybetmekten', 'doğum ağrıları ve doğum sırasında sorun gelişmesinden', 'doğum ağrıları ve doğumun bedenlerinde bırakacağı etkiden', 'doğum sonrası bedenlerinin bir daha eskisi gibi olmayacağından korktukları bulundu (sırasıyla $<0.001,<0.001,<0.001, p=0.016, p=0.016<0.001,<0.001$, $<0.001,<0.001)$.Gebelik öncesi doğum korkusu ölçeğinin sonuçlarının gebelik sayısına göre karşılaştırııması Tablo 3 'te verildi.

\section{Tartışma}

Gebeliğin ilk üç ayındaki gebeler doğum ağrıları ve doğumun bedeninde bırakacağı etkiler konusunda kaygılı iken gebeliğin üçüncü üç ayında doğum eylemi ve bebeğin sağlığı ile ilgili kaygılar ön plana çıkmaktadır.

Literatürde genç kadınlarda doğum korkusunun daha fazla olduğu bildirilmiştir (22-24). Bu çalışmada literatürle uyumlu olacak şekilde yaş azaldıkça doğum korkusunun arttığı bulundu. Düşük eğitim seviyesinin artmış doğum korkusu ile ilişkili olduğunu bildiren çalışmalar vardır $(23,24)$. Eğitim düzeyi ile doğum korkusunun ilişkisi olmadığını iddia eden yayınlarda mevcuttur (19). Bu çalışmada eğitim düzeyi arttıkça doğum korkusunun arttığı bulundu. Bunun nedeni eğitim düzeyi düşük olan gebelerin daha çok multiparlardan oluşmasından kaynaklanıyor olabilirLiteratürde bir işte çalışmayanlarda, çalışanlara göredoğum korkusunun fazla olduğu bildirilmiştir $(5,25)$. Bu çalışmamızda literatürden farklı olarak çalışma durumu ile doğum korkusu arasında bir ilişki bulunamamıştır. Çalışmamızda gebelerin tamamına yakını çalışmamaktadır. Bu nedenle çalışma durumu ile doğum korkusu arasında bir ilişki bulunamamış olabilir.

Doğum korkusunu ölçen değişik ölçekler vardır $(18,26,27)$. Ölçeklerde doğum korkusu ilgilendiren vücut bütünlüğü, doğum eylemi ve bebeğin sağlığı ile ilgili sorular bulunmaktadır. Nieminen ve ark. doğum korkusu düzeyinin gebelik haftası ile ilişkisiz olduğunu bildirmişlerdir (16). Benzer şekilde bu çalışmada doğum korkusu anket puanı gebelik haftası açısından benzer bulundu. Ancak anket sorularından bazılarının puanlarının gebelik haftasına göre değiştiği bulundu. Hastaların doğum ağrılarının şiddetli olma ihtimali nedeniyle duyulan endişe, doğum eylemi sırasında panikleme, doğum sırasında sorun çıkmasından korkma ve doğumda bebeğe zarar gelmesi konusundaki endişeler üçüncü üç ayındaki gebelerin temel korkularını oluşturmaktadır. Rouhe ve ark. nullipar gebelerde, gebelik haftası ilerledikçe doğum korkusunun arttığını bulmuşlardır (3). Doğumun kadınların vücudunda bırakacağı etki konusundaki kaygılar ise özellikle primigravid gebeliğin başlarında daha önemli hale gelmektedir. Fairbrother ve ark. benzer şekilde doğumda cinsel haz ve çekiciliği kaybetme korkusunun nullipar gebelerde erken gebelik haftalarında artığını bulmuşlardır (18). Daha önceki 
çalışmalarda doğum korkusu ile gebelik haftası arasında bir ilişki bulunamamıştır $(16,18,19)$. Bu çalışmada ise özellikle doğum ağrıları, doğum eylemini ve doğumda bebeğe zarar gelme endişesi gebelik haftası ile birlikte arttığı bulunmuştur. Doğum korkusunun primigravid gebelerde daha fazla olduğu bilinmektedir $(5,16,17)$. Bu çalışmada literatürde benzer şekilde doğum korkusu ölçek puanı primigravidlerde fazla bulunmuştur.Gebe bilgilendirme sınıflarında eğitim verilmekte olup, eğitim sırasında rutin olarak gebelerin doğum korkusu ölçek ile belirlenmemektedir. Gebelik bilgilendirme sınıflarında doğum korkusu fazla olan gebeler belirlenip, korkusu fazla olanlara özel eğitimler verilmesi faydalı olabileceğini düşünüyoruz. Özellikle eğitimlerin doğum korkusunun arttığı gebeliğin son haftalarında yoğunlaştırmak gerekirse psikolojik destek sağlanmasının olumlu katkıları olacağını düşünmekteyiz. Verilen eğitimlerin doğum korkusunu azaltmaya yönelik etkisi ve sezaryen oranlarına etkisi bu çalışmanın amacı ve kapsamı dışındadır. Bu konular ayrı birer çalışma konusu olabilir.

\section{Kaynaklar}

1. http://www.tuik.gov.tr/PreHaberBultenleri.do?id=27588

2. Poikkeus P, Saisto T, Unkila-Kallio L, Punamaki RL, Repokari L, Vilska S, et al. Fear of childbirth and pregnancy-related anxiety in women conceiving with assisted reproduction. Obstet Gynecol 2006;108:70-6. [CrossRef]

3. Rouhe H, Salmela-Aro, K, Halmesmäki, E, Saisto, T. Fear of childbirth according to parity, gestational age, and obstetric history. BJOG. Int J Obstet Gynaecol 2009;116:67-73. [CrossRef]

4. Fava GA, Grandi S, Michelacci L, Saviotti F, Conti S, Bovicelli L, et al. Hypochondriacal fears and beliefs in pregnancy. Acta Psychiatrica Scandinavica 1990;82:70-2. [CrossRef]

5. Melender HL. Fears and coping strategies associated with pregnancy and childbirth in Finland. J Midwifery Womens Health 2002;47:25663. [CrossRef]

6. Szeverenyi P, Poka R, Hetey M, Torok Z. Contents of childbirth-related fear among couples wishing the partner's presence at delivery. J Psychosom Obstet Gynecol 1998;19:38-43. [CrossRef]

7. Geissbuehler V, Eberhard J. Fear of childbirth during pregnancy: a study of more than 8000 pregnant women. J Psychosom Obstet Gynecol 2002;23:229-35. [CrossRef]

8. Sercekus $P$, Okumus $H$. Fears associated with childbirth among nulliparous women in Turkey. Midwifery 2009;25:155-62. [CrossRef]

9. Adams SS, Eberhard-Gran M, Eskild A. Fear of childbirth and duration of labour: a study of 2206 women with intended vaginal delivery. Int J Obstet Gynaecol 2012;119:1238-46. [CrossRef]

10. Sydsjö G, Angerbjörn L, Palmquist S, Bladh M, Sydsjö A, JosefssonA. Secondary fear of childbirth prolongs the time to subsequent delivery. Acta Obstet Gynecol Scand 2013;92:210-4. [CrossRef]

11. Hofberg K, Brockingtong I. Tokophobia: an unreasoning dread of childbirth. A series of 26 cases. Br J Psychiatry 2000;176:83-5. [CrossRef]

12. Wax JR, Cartin A, Pinette MG, Blackstone J. Patient choice cesarean: an evidence-based review. Obstet Gynecol Surv 2004;59:601-16. [CrossRef]
Çalışmanın güçlü yönleri ve limitasyonları:

Bu çalışmada gebelerin doğum korkuları gebelik haftalarına göre analiz edildi. Doğum korkusunun farklı yönlerinin gebelik haftasına göre değiştiği bulundu. Bu açıdan literatüre önemli katkı sağlanmıştır.

Gebelere eğitim öncesi ve sonrası doğum korkusu doldurtulmuş olsaydı, gebelik bilgilendirme sınıfında verilen eğitimin etkisi değerlendirilebilirdi. Eğitim öncesi dönemde gebelere doğum korkusu anketi doldurtulmaması çalışmanın limitasyonu sayılabilir.

\section{Sonuçlar}

Gebeliğin ilk aylarındakiler doğumun bedeninde bırakacağı etkiler konusunda kaygı duymaktadırlar. Gebelik ilerledikçe doğum eylemi ile başa çıkamama ve bebeğin sağIığı ile ilgili kaygılar ön plana çıkmaktadır Doğum korkusu primigravidlerde daha fazladır. Gebeliğin son haftalarında özellikle primigravid gebelerin doğum korkularını azaltacak eğitimlere ağırlık verilmelidir.

13. Song B, Fang L. W, Zhou Y, Peng ZZ. Cesarean section due to social factors and its influencing factors in pregnant women. Chin J Public Health 2010;26:533-4.

14. Wiklund I, Andolf E, Lilja H, Hildingsson I. Indications for cesarean section on maternal request - guidelines for counseling and treatment. Sex Reprod Health 2012;3:99-106. [CrossRef]

15. D'Souza R. Caesarean section on maternal request for non-medical reasons: putting the UK National Institute of Health and Clinical Excellence guidelines in perspective. Best Pract Res Clin Obstet Gynaecol 2013;27:165-77. [CrossRef]

16. Nieminen K, Stephansson O, Ryding EL. Women's fear of childbirth and preference for cesarean section - a cross-sectional study at various stages of pregnancy in Sweden. Acta Obstet Gynecol Scand 2009;88:807-13. [CrossRef]

17. Toohill J, Fenwick J, Gamble J, Creedy DK. Prevalence of childbirth fear in an Australian sample of pregnant women. BMC Pregnancy Childbirth 2014;14:e1-10. [CrossRef]

18. Fairbrother N, Thordarson DS, Stoll K. Fine tuning fear of childbirth: the relationship between Childbirth Fear Questionnaire subscales and demographic and reproductive variables. J Reprod Infant Psychol 2018;36:15-29. [CrossRef]

19. Mortazavi F, Agah J. Childbirth Fear and Associated Factors in a Sample of Pregnant Iranian Women. Oman Med J 2018;33:497-505. [CrossRef]

20. https://dosyaism.saglik.gov.tr/Eklenti/12616,20140925-85-hskdangebe-bilgilendirme-sinifi-hakkinda-genelge-2014-28pdf.pdf?0

21. Uçar T, Taşhan ST. Gebelik öncesi doğum korkusu ölçeğinin Türkçe uyarlaması: kadın ve erkeklerde geçerlik ve güvenirlik çalışması. ACU Sağlık Bil Derg 2018;9:289-96. [CrossRef]

22. Elevander $\mathrm{C}$, Cnattingius $\mathrm{S}$, Kjerulff $\mathrm{KH}$. Birth experience in women with low, intermediate or high levels of fear: Findings from the first baby study. Birth 2013;40:289-96. [CrossRef]

23. Gao L, Liu XJ, Fu BL, Xie W. Predictors of childbirth fear among pregnant Chinese women: A cross-sectional questionnaire survey. Midwifery 2015;31:865-70. [CrossRef] 
24. Laursen M, Hedegaard M, Johansen C. Fear of childbirth: Predictors and temporal changes among nulliparous women in the Danish National Birth Cohort. Int J Obstet Gynaecol 2008;115:354-60. [CrossRef]

25. Saisto T, Salmela-Aro K, Nurmi JE, Halmesmäki E. Psychosocial characteristics of women and their partners fearing vaginal childbirth. Int J Obstet Gynaecol 2001;108:492-8. [CrossRef]
26. Wijma K, Wijma B, Zar M. Psychometric aspects of the W-DEQ; a new questionnaire for the measurement of fear of childbirth. J Psychosom Obstet Gynaecol 1998;19:84-97. [CrossRef]

27. Stoll K, Hauck Y, Downe S, Edmonds J, Gross MM, Malott A, et al. Cross-cultural development and psychometric evaluation of a measure to assess fear of childbirth prior to pregnancy. Sex Reprod Healthc 2016;8:49-54. [CrossRef] 